\title{
Rupture process at the beginning of the 2007 Chuetsu-oki, Niigata, Japan, earthquake
}

\author{
Hiroshi Takenaka ${ }^{1}$, Yosuke Yamamoto ${ }^{2}$, and Hirokazu Yamasaki ${ }^{1}$ \\ ${ }^{1}$ Department of Earth and Planetary Sciences, Kyushu University, 6-10-1 Hakozaki, Fukuoka 812-8581, Japan \\ ${ }^{2}$ Geo-Research Institute, 4-3-2 Itachibori, Osaka 550-0012, Japan
}

(Received January 27, 2008; Revised September 16, 2008; Accepted September 17, 2008; Online published February 18, 2009)

\begin{abstract}
The rupture process at the beginning stage of the 2007 Chuetsu-oki, Niigata, Japan, earthquake $\left(M_{\mathrm{W}} 6.6\right)$ is investigated by analyzing $P$-wave records from local strong-motion stations. The $P$-wave portion of the nearsource strong-motion records shows about $2 \mathrm{~s}$ of small but increasing amplitude arrival (so-called "initial rupture phase") followed by the onset of the main energy release ("main rupture phase"). Two issues are addressed in this paper: (1) where the initial rupture process occurred and (2) where the seismic energy corresponding to the main rupture phase was released at the primary stage of the main rupture. The first issue is addressed by locating the main rupture onset position, and the second issue is then approached by introducing a method for mapping the wave energy onto plausible fault planes. Eventually, the following were revealed. The rupture initiated and propagated on the NW-dipping plane, which is a nodal plane of the focal mechanism solution. At $2.1 \mathrm{~s}$ after rupture initiation the subsequent main rupture started at a position of approximately $4 \mathrm{~km}$ away, southwestward and updipward from the hypocenter. The main rupture at this stage has two possible rupture planes: the same plane as the initial rupture plane, and the conjugated plane, which shares the main rupture onset point with the initial rupture plane. Although it is difficult to determine which plane was actually ruptured at the primary stage of the main rupture, we found that the possible areas radiating strong wave energy on the two possible planes, which could correspond to the first asperity of this earthquake, are located between the hypocenter and the Kashiwazaki-Kariwa nuclear power plant.
\end{abstract}

Key words: 2007 Chuetsu-oki earthquake, fault plane, source process, initial rupture, asperity.

\section{Introduction}

The 2007 Chuetsu-oki, Niigata, Japan, earthquake $\left(M_{\mathrm{W}} 6.6, M_{\mathrm{JMA}} 6.8\right)$ occurred at 10:13 on 16 July 2007 $(\mathrm{JST}=\mathrm{UT}+9$ hours) offshore from western Niigata Prefecture, Japan, and strongly shook the near-source area. The Kashiwazaki-Kariwa nuclear power plant of the Tokyo Electric Company (TEPCO) was about $14 \mathrm{~km}$ away from the epicenter, and a peak horizontal acceleration of $2058 \mathrm{~cm} / \mathrm{s}^{2}$ was recorded in the turbine building of unit 3 (located between stations KKZ1 and KKZ5 in Fig. 1). The focal area spreads southwestward from the epicenter, about $30 \mathrm{~km}$ along the coastal line, and the mainshock has a steeply dipping reverse fault mechanism under the eastwest compression (Fig. 1).

The focal mechanism would lead us to expect that most of the aftershocks would distribute along a single northwestward-dipping (NW-dipping) or southeastwarddipping (SE-dipping) plane, which is one of the nodal planes of the fault mechanism solution. However, the aftershock distribution may not be so simple that a single fault plane would be identified. Kato et al. (2008) inverted the arrival times from aftershocks observed by a dense seismic network deployed immediately after the mainshock and

Copyright (c) The Society of Geomagnetism and Earth, Planetary and Space Sciences (SGEPSS); The Seismological Society of Japan; The Volcanological Society of Japan; The Geodetic Society of Japan; The Japanese Society for Planetary Sciences; TERRAPUB. found that the aftershock distribution has lateral heterogeneity along the fault strike: at the northeast area the aftershocks are aligned along both the NW- and SE-dipping planes, while from the center to the southwest area most events are aligned along the SE-dipping plane. Similar patterns of aftershocks were also observed by Sakai et al. (2007), Shinohara et al. (2008), and Yukutake et al. (2008). Based on the configuration of the mainshock hypocenter and the aftershock distribution, Kato et al. (2008) speculated that rupture of the mainshock may have initiated on the NW-dipping plane and then transferred to the conjugated fault plane (i.e., the SE-dipping plane).

In this paper, we focus on the initial stage of the rupture. We analyze the $P$-wave portion before the $S$-wave arrival of the mainshock records at strong-motion stations near the source area to investigate the rupture process during about the first $5 \mathrm{~s}$ after the rupture initiation. In Fig. 1 we show the locations of the strong-motion stations from which we observed the records used in this paper. There are 25 stations, and the epicentral distances of the stations are less than $65 \mathrm{~km}$. In all stations except station KZK (F-net) ground acceleration is recorded, while at KZK ground velocity is recorded. The F-net as well as the K-NET and the KiK-net belongs to the National Research Institute for Earth Science and Disaster Prevention (NIED). Although the Fnet is a network for broadband seismic observation, each station of the network also has a strong-motion seismome- 


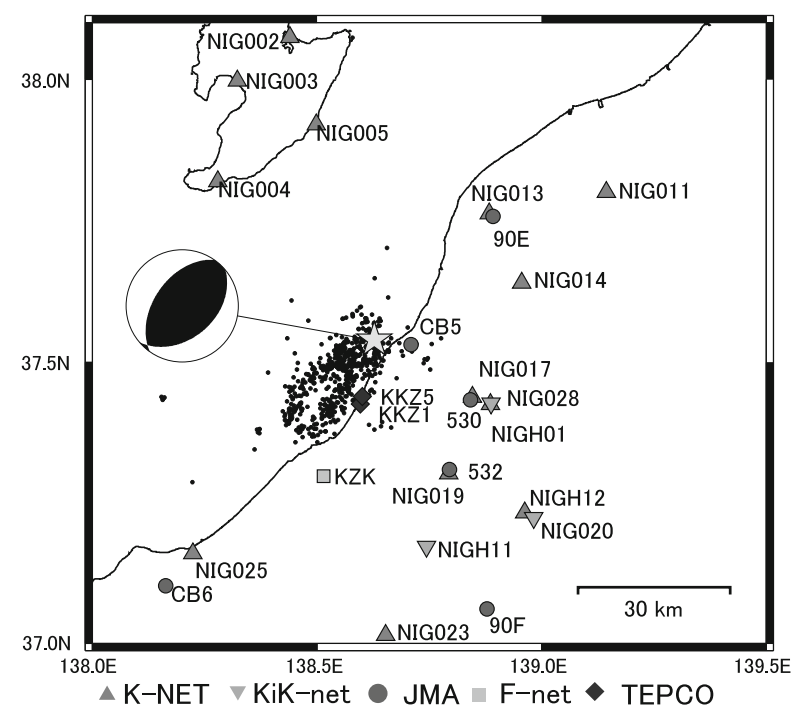

Fig. 1. Map showing the epicenter of the mainshock (light star) with the focal mechanism and the locations of the strong-motion stations whose records are used in this paper. The focal mechanism comes from the F-net CMT solution (NIED, 2007; http://www.hinet.bosai.go.jp/topics/ niigata070716/mechanism_j.html). The aftershock distribution until 31 July 2007 , as determined by JMA, is also plotted.
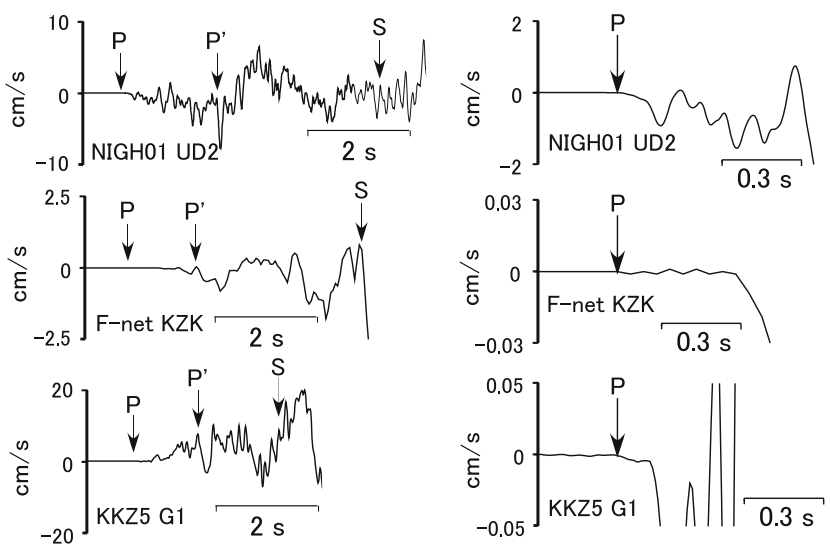

Fig. 2. Examples of the observed seismograms near the focal region. The traces are all UD-components of velocity records which were obtained from the integration of the acceleration records originally observed at all stations except KZK (F-net), which records velocity. The whole $P$-wave portion of the records is indicated in the left column, and the early part of each trace in the left column is zoomed in the right column so that the first arrival of $P$ wave is visible. The records show that the initial rupture phase $(P)$ followed by the onset of the main rupture phase $\left(P^{\prime}\right)$. The $S$-wave arrival is also shown.

ter installed with a high-sensitivity broadband seismometer. The stations of the JMA (Japan Meteorological Agency) are used for measuring seismic intensity where strong ground motion is recorded. Stations KKZ1 and KKZ5 are at units 1 and 5 of the Kashiwazaki-Kariwa TEPCO nuclear power plant, respectively.

The $P$-wave records observed at the stations in Fig. 1 show nearly $2 \mathrm{~s}$ of small but increasing amplitude arrival, the so-called initial rupture phase, followed by the onset of the main energy release, the so-called main rupture phase (Fig. 2). The sequence of the initial rupture and main rupture phases has been observed from teleseismic or strongmotion records of other earthquakes (e.g., the 1989 Loma
Prieta earthquake: Wald et al., 1991; the 1992 Landers earthquake: Abercrombie and Mori, 1994; the 2000 Western Tottori earthquake: Hirata et al., 2002; the 2005 West Off Fukuoka Prefecture earthquake: Takenaka et al., 2006; the 2007 Noto Hanto earthquake: Yamamoto and Takenaka, 2007).

In this paper we consider the following two issues: where the initial rupture process occurred, and how it evolved at the primary stage of the subsequent main rupture. In order to address these issues, we first determine the location and time of the main rupture onset using the differential arrival time of the initial rupture and main rupture phases, and then we introduce a method for mapping the wave energy of the main rupture onto plausible fault planes.

\section{Location of the Main Rupture Onset}

We measured the arrival times of the initial $P$ phase and the main rupture phase $P^{\prime}$ on the records at the strongmotion stations in Fig. 1. Figure 3(a) shows a plot of differences between the arrival times of $P$ and $P^{\prime}$ against the station azimuths, and Fig. 3(b) is a plot of the differential arrival times versus hypocentral distance. The plot in Fig. 3(a) has a minimum around the azimuth of $\mathrm{N} 200^{\circ} \mathrm{E}$ and a maximum at an azimuth $180^{\circ}$ apart from the minimum position, which suggests that the main rupture onset point is located in the direction of nearly $\mathrm{N} 200^{\circ} \mathrm{E}$ from the hypocenter. Figure 3(b) indicates that the differential arrival time and hypocentral distance are independent of each others. Hirata (2003) and Yamaguchi et al. (2007) demonstrated the following two conditions as criteria for confirming the identification of $P^{\prime}$ through analyses of local seismograms from the 2000 Western Tottori earthquake and the 2005 West Off Fukuoka Prefecture earthquake, respectively: one is that the differential arrival time has no dependence on hypocentral distance, and the other is that the plot of the differential arrival time versus the station azimuth has only one set of minimum and maximum points, which are located $180^{\circ}$ apart each other. Figures 3(a) and (b) show that our identified $P^{\prime}$ satisfies the criteria.

We now locate the main rupture onset point on the fault plane. Assuming the fault plane to be one of the two nodal planes (i.e., the NW-dipping and SE-dipping planes) of the focal mechanism solution (Fig. 1), we search the onset position over each plane by applying the master-event-like technique used by Takenaka et al. (2006) to the measured differential arrival times between the $P$ and $P^{\prime}$ phases. In this technique the rupture time (or the mean rupture velocity) and the $2 \mathrm{D}$ coordinates of the main rupture onset position are determined with a grid search method. These values are considered to be an optimal set of relative values with respect to those of the hypocenter to minimize the residuals of the differential arrival times. We employ the hypocenter location (lat. $\mathrm{N} 37.5407^{\circ}$, long. E138.6258 ${ }^{\circ}$, depth $11.96 \mathrm{~km}$ ) determined by Sakai et al. (2007) and the 1D $P$-wave velocity model of the JMA2001 (Ueno et al., 2002). This technique is robust and insensitive to uncertainties in hypocenter and velocity structure (Takenaka et al., 2006).

Figures 4(a) and (b) show the optimal position searched on each of the NW-dipping and SE-dipping planes, together with the contours of the mean squared residuals. The op- 
(a)

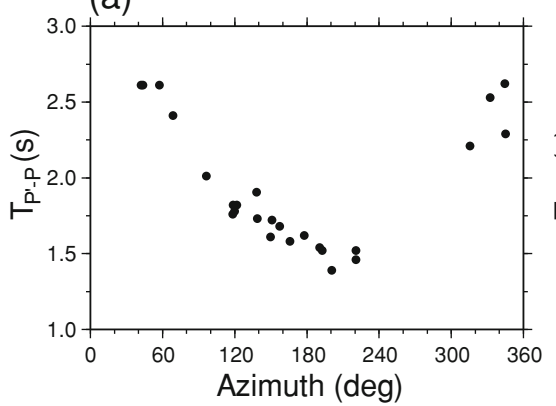

(b)

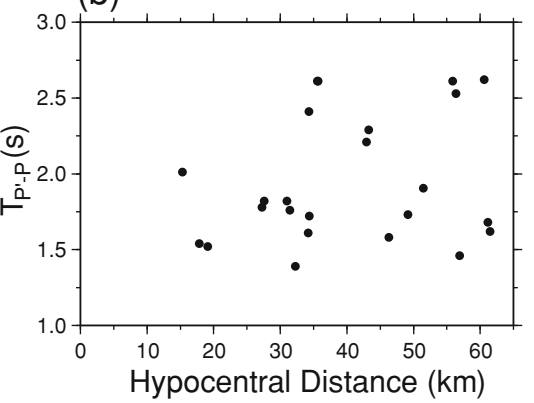

Fig. 3. (a) Azimuthal dependence of the arrival time difference between the initial $P$ phase and the main rupture onset phase $P^{\prime}, T_{P^{\prime}-P}$. (b) Plot of $T_{P^{\prime}-P}$ versus hypocentral distance.
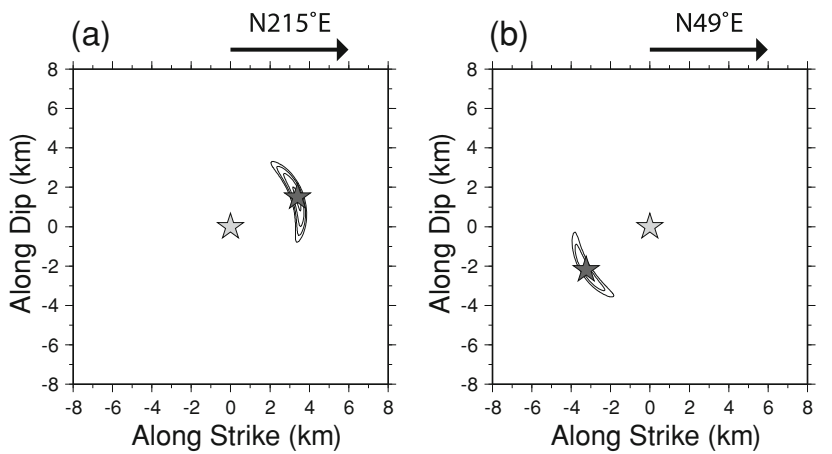

(c)

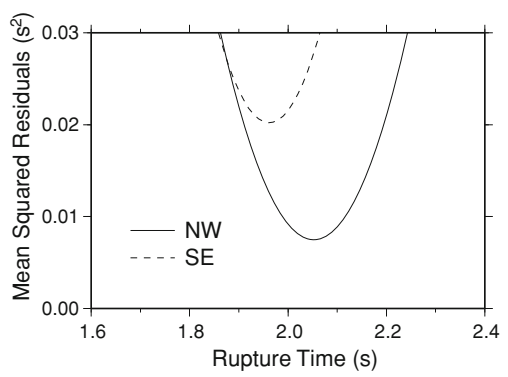

Fig. 4. The optimal position of the main rupture onset searched over each nodal plane of the focal mechanism solution. (a) NW-dipping plane and (b) SE-dipping plane. The optimal position of the main rupture onset is given by a dark star on each assumed plane. The origin of the coordinates is the hypocenter, indicated by a light star. The contours are also plotted on each plane for the mean squared residuals of $0.04 \mathrm{~s}^{2}$ or less, which corresponds to the rms residual time of $0.2 \mathrm{~s}$ or less, at intervals of $0.01 \mathrm{~s}^{2}$. (c) Mean squared residuals in locating the main rupture onset point for each assumed planes. They are plotted against the rupture time of the main rupture onset.

timal position is located $3.4 \mathrm{~km}$ southwestward along the strike and $1.5 \mathrm{~km}$ upward along the dip from the hypocenter for the NW-dipping plane, while that for the SE-dipping plane is $3.3 \mathrm{~km}$ southwestward along the strike and $2.2 \mathrm{~km}$ downward along the dip from the hypocenter. The optimal rupture time is $2.1 \mathrm{~s}$ for the NW-dipping plane and $2.0 \mathrm{~s}$ for the SE-dipping plane (Fig. 4(c)). The mean rupture velocities for this rupture stage are then $1.8 \mathrm{~km} / \mathrm{s}$ and $2.0 \mathrm{~km} / \mathrm{s}$, respectively. Figure 4(c) indicates that the minimum value of the mean squared residuals for the NW-dipping plane is considerably smaller than that for the SE-dipping plane. This strongly suggests that the rupture started on the NWdipping plane and propagated on this plane during the initial rupture process. The line passing through the hypocen- ter and the estimated main rupture onset point on the NWdipping plane intersects the ground surface just around station KZK (F-net) with an azimuth of almost $\mathrm{N} 200^{\circ} \mathrm{E}$ from the epicenter, which is in good relation to the minimum in Fig. 3(a). In the next section we examine the subsequent rupture process that generates the main rupture phase.

\section{Imaging of the Main Rupture}

We consider two possible models for the primary stage (about $3 \mathrm{~s}$ ) of the main rupture: one is that the main rupture propagates on the same NW-dipping plane as the initial rupture (Model 1 in Fig. 5), and the other is that the rupture is transferred from the initial rupture plane to the conjugated fault plane (i.e., the SE-dipping plane) at the main rupture onset point and then propagates on the SE-dipping plane (Model 2 in Fig. 5). In this paper we are investigating only the rupture process during the first $5 \mathrm{~s}$ after the rupture initiation as mentioned in Section 1, and Model 1 may include all cases that the rupture is transferred to the SEdipping plane at a later time.

In order to see where the seismic energy of the main rupture phase was radiated, we introduce a method to map the source distribution, which is similar to the Source Scanning Algorithm proposed by Kao and Shan (2004) for locating a tremor event and the back-projection method employed by Ishii et al. (2005) for imaging the rupture of the 2004 Sumatra-Andaman earthquake from the teleseismic array data. We calculate the 'radiation strength' $s(\boldsymbol{\xi})$ of a point $\boldsymbol{\xi}$ on the two possible fault planes, defined as

$$
\begin{aligned}
s(\boldsymbol{\xi})= & \max \left\{f(\boldsymbol{\xi}, \tau): \tau_{1} \leq \tau \leq \tau_{2}\right\}, \\
f(\boldsymbol{\xi}, \tau)= & (1 / M) \sum_{m=0}^{M}\{(1 / N) \\
& \left.\cdot \sum_{n=1}^{N}\left[\left(p_{n} / A_{n}\right) u_{n}\left(\tau+t_{n}(\boldsymbol{\xi})+m \Delta t\right)\right]\right\}^{2},
\end{aligned}
$$

where $\tau$ is the time from the main rupture onset, and $u_{n}(t)$ is the vertical component velocity record of the $n$th station at time $t . p_{n}$ and $A_{n}$ are the polarity and the rms amplitude of the record, respectively, and $N$ is the number of stations. $t_{n}(\boldsymbol{\xi})$ is the $P$-wave travel time from source point $\boldsymbol{\xi}$ to the $n$th station. $\Delta t$ is the sampling period of $u_{n}(t)$, and $M$ is the number of points within a chosen time window over which the squared amplitude of the stacked records 


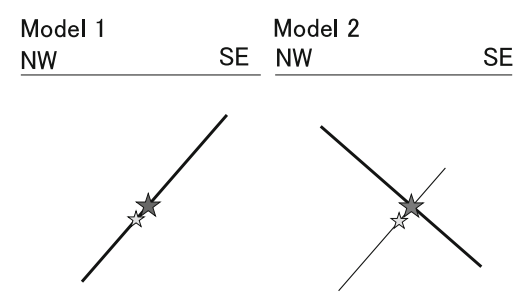

Fig. 5. Vertical cross-section along the NW-SE direction. Two possible models for the rupture propagation at the beginning main rupture stage. The bold line in each model indicates the fault plane where the rupture propagates at the beginning stage of the main rupture. The thin line of Model 2 shows the initial rupture plane. The light and dark stars indicate the hypocenter and the estimated main rupture onset location (Fig. 4(a)), respectively.
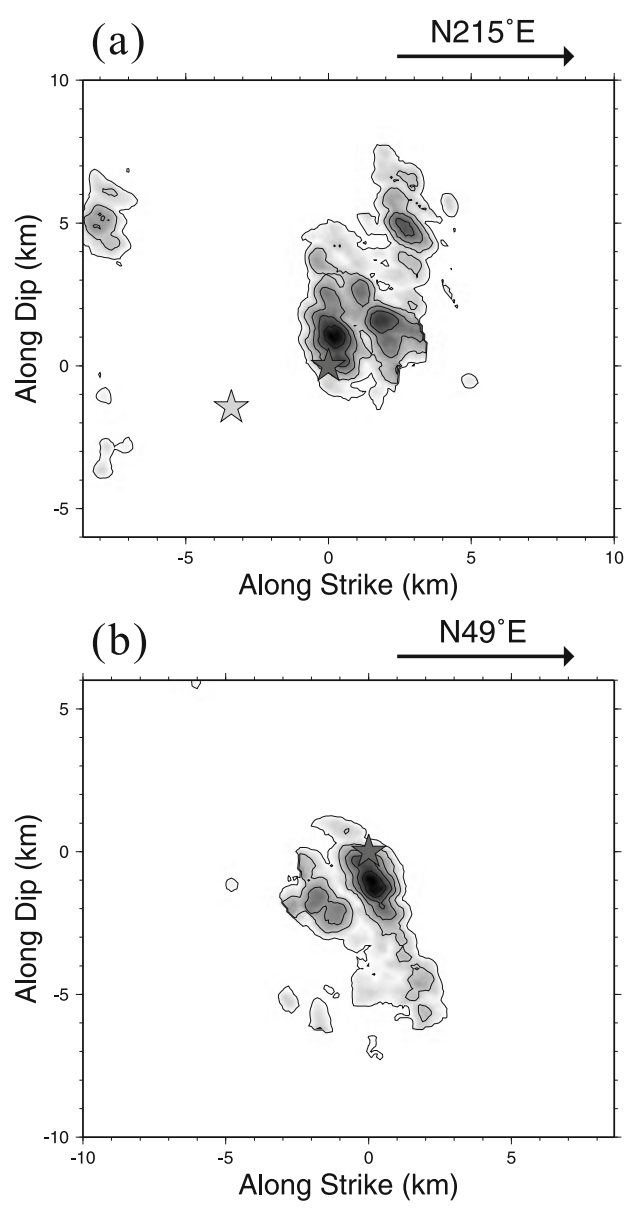

Fig. 6. Radiation strength images on (a) the NW-dipping plane of Model 1 and (b) the SE-dipping plane of Model 2, during the first $3 \mathrm{~s}$ after the main rupture onset. The line contours are plotted on the plane of each model at increments of $10 \%$ starting at $50 \%$ of the maximum value over the plane. The light and dark stars indicate the hypocenter and the estimated main rupture onset location (Fig. 4(a)), respectively.

are averaged. Using Eq. (1), stacking of the records from all stations constructively sums the wave energy radiated from the given source point and cancels out other energy present in the records.

In the calculation of the radiation strength we use the records at the stations used in Section 2 except for seven stations NIG028, CB5, KKZ1, KKZ5, 530, 532, and 90E. The first four stations are so close to the hypocenter that their records are not long enough for the main rupture phase, and the last three stations are located too close to a number of other stations. The sampling periods and $M$ are set to be $0.01 \mathrm{~s}$ and 16 , respectively.

Figure 6 shows the calculated radiation strength images during the first $3 \mathrm{~s}$ after the main rupture onset (i.e., $0 \leq$ $\tau \leq 3$ (s)), on the two possible main rupture planes: the NW-dipping plane of Model 1, and the SE-dipping plane of Model 2. The highest peak values over the NW-dipping plane and the SE-dipping plane are 0.730 and 0.747 , respectively, and the two values are almost equal. The shaded area around the main rupture onset point in each model indicates the possible area where a relatively large amount of seismic energy could have been radiated, corresponding to the "asperity". In both models, the radiation strength in the "asperities" increases sharply around the main rupture onset point, which seems to be located near the boundaries of the "asperities", and the size of the "asperity" areas of the two models is almost the same. A similar configuration of asperity and the main rupture starting position was observed for the 2005 West Off Fukuoka Prefecture earthquake (Takenaka et al., 2006). In the next section we discuss the "asperities" we imaged here.

\section{Discussion}

Figure 7 displays the strong-motion records observed at stations KKZ1 and KKZ5 near the focal area. Three major events ( $S$ waves) are seen on these records, indicated as 'Asp.1', 'Asp.2' and 'Asp.3'. Irikura et al. (2007) and Miyake and Koketsu (2007) considered that the mainshock has three asperities and that each event on the records had been generated in the main by each corresponding asperity. The "asperities" that were imaged in the previous section could belong to the first asperity that generates the first large pulse (Asp.1) on the strong-motion records at KKZ1 and KKZ5.

Figure 8 shows the geographical location of the "asperities" for Models 1 and 2 (Fig. 6), together with the hypocenter and the main rupture onset position. Since the projections of the "asperities" from the two models onto the surface are almost identical, they are plotted as one area in Fig. 8. This area indicates that the first asperity is located between the hypocenter and station KKZ5. In Model 1 the main rupture on the NW-dipping plane propagates toward the ground surface from the onset position (Fig. 6(a)), while

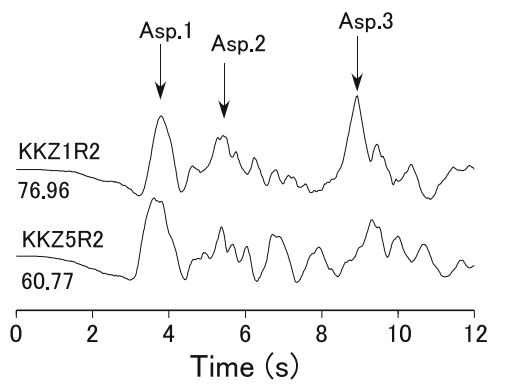

Fig. 7. Strong-motion records at stations KKZ1 and KKZ5. The traces are the NS components of the velocity records. Time zero of each trace is set to be at the first $P$-wave arrival. The arrows show the peaks of the pulses that Irikura et al. (2007) and Miyake and Koketsu (2007) interpreted to be generated at three asperities. 


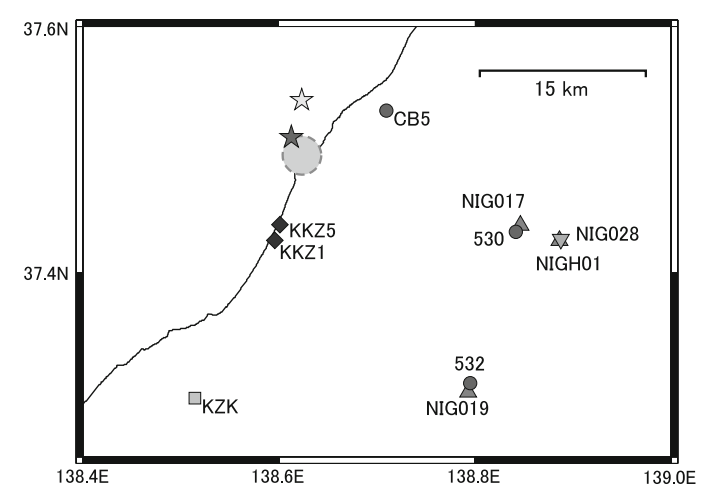

Fig. 8. Geographical configuration of the hypocenter, the main rupture onset position, and the imaged "asperities". The surface projections of "asperities" of Models 1 and 2 are plotted as one area (lightly shaded circle), because they are almost identical. The epicenter and the projected main rupture onset position are given by a light star and a dark star, respectively.

in Model 2 the main rupture propagates downward on the SE-dipping plane (Fig. 6(b)). The configuration of the "asperities", the hypocenter, and the main rupture onset position suggest that in the case of Model 1, the Kashiwazaki area, where stations KKZ1 and KKZ5 are located, might have suffered the effect of the forward rupture directivity during the first asperity break.

\section{Conclusions}

Analyzing $P$-waves on the local strong-motion records from the 2007 Chuetsu-oki, Niigata, earthquake, we have elucidated the rupture process during the first $5 \mathrm{~s}$ after the rupture initiation. The rupture initiated and propagated on the NW-dipping plane, which is a nodal plane of the focal mechanism, radiating a relatively small amount of seismic energy, for $2.1 \mathrm{~s}$. The subsequent main rupture, which radiated greater energy, started at a position approximately $4 \mathrm{~km}$ away, southwestward and updipward from the hypocenter. The main rupture at this stage (next $3 \mathrm{~s}$, i.e., up to $5 \mathrm{~s}$ after the initial rupture started) has two possible rupture planes: one is the same NW-dipping plane as the initial rupture plane, and the other is the SE-dipping plane, which is a conjugated plane of the initial rupture plane and shares the main rupture onset point with the initial rupture plane. Although we could not determine which plane was actually ruptured at the beginning main rupture stage, we estimated the possible areas radiating large wave energy on the two planes. We found that these strong radiation areas, which could correspond to the first asperity of this earthquake, are located between the hypocenter and the Kashiwazaki-Kariwa nuclear power plant.

Acknowledgments. We are grateful to Drs. A. Kato, T. Nakamura, and Y. Yukutake, and Profs. K. Koketsu and S. Sakai for valuable discussions. Prof. S. Sakai kindly provided us with information on his located hypocenter of the mainshock, and Dr. A. Kato also gave us a preprint of his submitted paper. Dr. T. Nakamura kindly helped us to make our final manuscript in the LaTeX format. We used the strong-motion records supplied by the National Institute for Earth Science and Disaster Prevention (K-NET, KiK-net, F-net), the Japan Meteorological Agency, and the Tokyo Electric Power Company. The comments from Profs. J. Zahradnik and $\mathrm{K}$. Yomogida and those from an anonymous reviewer were very helpful for improving the manuscript. Most of the figures were created using GMT (Wessel and Smith, 1995). This study are partially supported by "Special Project for Earthquake Disaster Mitigation in Metropolitan Tokyo Area".

\section{References}

Abercrombie, R. and J. Mori, Local observations of the onset of a large earthquake, 28 June 1992 Landers, California, Bull. Seismol. Soc. Am., 84, 725-734, 1994.

Hirata, M., The Initial Rupture Process of 2000 Western Tottori Earthquake, 28 pp., Master Thesis, Kyoto University, 2003.

Hirata, M., Y. Umeda, and H. Kawakata, Initial rupture of the 2000 Western Tottori earthquake, Chikyu Monthly, special issue, 38, 162-166, 2002 (in Japanese).

Irikura, K., T. Kagawa, K. Miyakoshi, and S. Kurahashi, Rupture process and strong ground motions of the 2007 Niigataken Chuetsu-Oki earthquake-Directivity pulses striking the Kashiwazaki-Kariwa $\mathrm{Nu}$ clear Power Plant-, AGU, Fall Meeting, S31B-0441, 2007.

Ishii, M., P. M. Shearer, H. Houston, and J. E. Vidale, Rupture extent, duration, and speed of the 2004 Sumatra-Andaman earthquake imaged by the Hi-Net array, Nature, 435, doi:10.1038/nature03675, 2005.

Kao, H. and S.-J. Shan, The source-scanning algorithm: Mapping the distribution of seismic sources in time and space, Geophys. J. Int., 157, 589-594, 2004.

Kato, A., S. Sakai, E. Kurashimo, T. Igarashi, T. Iidaka, N. Hirata, T. Iwasaki, T. Kanazawa, and Group for the aftershock observations of the 2007 Niigataken Chuetsu-oki Earthquake, Imaging heterogeneous velocity structures and complex aftershock distributions in the source region of the 2007 Niigataken Chuetsu-oki Earthquake by a dense seismic observation, Earth Planets Space, 60, 1111-1116, 2008.

Miyake, H. and K. Koketsu, Source modeling and broadband ground motion simulation for the 2007 Niigata-ken Chuetsu-oki earthquake, Seismol. Soc. Japan, Fall Meeting, P1-076, 2007 (in Japanese).

Sakai, S., A. Kato, E. Kurashimo, T. Igarashi, T. Iidaka, T. Iwasaki, N. Hirata, T. Kanazawa, and the group for the joint aftershock observation of the Niigataken Chuetsu-oki Earthquake in 2007, Aftershock observation of the Niigataken Chuetsu-oki Earthquake in 2007 by temporary seismic observations, Seismol. Soc. Japan, Fall Meet., P1-060, 2007 (in Japanese).

Shinohara, M., T. Kanazawa, T. Yamada, K. Nakahigashi, S. Sakai, R. Hino, Y. Murai, A. Yamazaki, K. Obana, Y. Ito, K. Iwakiri, R. Miura, Y. Machida, K. Mochizuki, K. Uehira, M. Tahara, A. Kuwano, S. Amamiya, S. Kodaira, T. Takanami, Y. Kaneda, and T. Iwasaki, Precise aftershock distribution of the 2007 Chuetsu-oki Earthquake obtained by using an ocean bottom seismometer network, Earth Planets Space, 60, 1121-1126, 2008.

Takenaka, H., T. Nakamura, Y. Yamamoto, G. Toyokuni, and H. Kawase, Precise location of the fault plane and the onset of the main rupture of the 2005 West Off Fukuoka Prefecture earthquake, Earth Planets Space, 58, 75-80, 2006.

Ueno, H., S. Hatakeyama, T. Aketagawa, J. Funasaki, and N. Hamada, Improvement of hypocenter determination procedures in the Japan Meteorological Agency, Q. J. Seismol., 65, 123-134, 2002 (in Japanese with English abstract).

Yamaguchi, S., H. Kawakata, T. Adachi, and Y. Umeda, Features of initial process of rupture for the 2005 West off Fukuoka Prefecture earthquake, Zisin (J. Seismol. Soc. Jpn.), 59, 241-252, 2007 (in Japanese with English abstract).

Yamamoto, Y. and H. Takenaka, Rupture process of the 2007 Noto Hanto earthquake inferred from local $P$-wave records: second hypocenter, initial rupture, main rupture, asperity and killer pulse, $A G U$, Fall Meeting, S13A-1059, 2007.

Yukutake, Y., T. Takeda, and K. Obara, Well-resolved hypocenter distribution using the double-difference relocation method in the region of the 2007 Chuetsu-oki Earthquake, Earth Planets Space, 60, 1105-1109, 2008.

Wald, D. J., D. V. Helmberger, and T. H. Heaton, Rupture model of the 1989 Loma Prieta earthquake from the inversion of strong-motion and broadband teleseismic data, Bull. Seismol. Soc. Am., 81, 1540-1572, 1991.

Wessel, P. and W. H. F. Smith, New version of the generic mapping tools released, Eos Trans. $A G U, \mathbf{7 6}, 329,1995$.

H. Takenaka (e-mail: takenaka@geo.kyushu-u.ac.jp), Y. Yamamoto, and H. Yamasaki 